\title{
Regional and Developmental Heterogeneity in Splicing of the Rat Brain NMDAR1 mRNA
}

\author{
D. J. Laurie and P. H. Seeburg \\ Laboratory of Molecular Neurobiology, Centre for Molecular Biology (ZMBH), University of Heidelberg, Heidelberg \\ D-69120, Germany
}

\begin{abstract}
Developmental and regional alternative splicing of the NMDAR1 subunit gene transcript was examined by in situ hybridization in the developing and adult rat brain. NMDAR1 mRNA, barely detectable at embryonic day 14, increased gradually during development until the third postnatal week, after which it declined slightly to adult levels, when it was detected in every examined neuronal type. Each splice form of the primary NMDAR1 gene transcript was found to follow a parallel profile of abundance in the brain, but marked regional differences were observed in splicing at both $5^{\prime}$ and $3^{\prime}$ sequences. The individual regional distributions of splice forms appeared to be established around birth, with little change thereafter, except in the overall abundance. The NMDAR 1-a and NMDAR 1-2 splice forms occurred extensively and approximately homogeneously throughout brain gray matter. The NMDAR1-b variant was found primarily in the sensorimotor cortex, neonatal lateral caudate, thalamus, hippocampal CA3 field, and cerebellar granule cells, but was absent from adult caudate. The NMDAR 1-1 and -4 splice forms were detected in almost complementary patterns; the former was concentrated in more rostral structures such as cortex, caudate, and hippocampus, while the latter was principally in more caudal regions such as thalamus, colliculi, and cerebellum. These two splice forms accounted for a greater proportion of the adult NMDAR1 mRNA than that of the neonate. The NMDAR1-3 mRNA variant was scarce, being detected only at very low levels in postnatal cortex and hippocampus. The different splice forms may generate regional differences in NMDA receptor properties during development and in the adult CNS.
\end{abstract}

[Key words: NMDA receptor, NMDAR1 mRNA, in situ hybridization, splice variants, rat brain, development]

The NMDA-selective type of cerebral glutamate ionotropic receptor is believed to have important roles in neuron differentiation and synapse consolidation in the developing brain (McDonald and Johnston, 1990; Yuste and Katz, 1991), and long-term potentiation (LTP), synaptic plasticity, and neurotoxicity in the adult brain (Collingridge and Singer, 1990; Meldrum and Garthwaite, 1990). Two families of subunits of this receptor have recently been cloned from rat brain and termed

\footnotetext{
Received July 23, 1993; revised Oct. 4, 1993; accepted Nov. 1, 1993.

We are grateful to $\mathrm{U}$. Keller for technical assistance. This work was supported by BMFT Grant BCT 364 A2 $321 / 7291$ and by funds of the German Chemical Industry.

Correspondence should be addressed to D. J. Laurie, Preclinical Research, Sandoz Pharmaceuticals Ltd., Basle, CH-4002 Switzerland.

Copyright (c) 1994 Society for Neuroscience $0270-6474 / 94 / 143180-15 \$ 05.00 / 0$
}

NMDAR1 and NMDAR2 (Moriyoshi et al., 1991; Monyer et al., 1992). The equivalent murine families are called $\zeta$ and $\epsilon$, respectively (Kutsuwada et al., 1992; Meguro et al., 1992; Yamazaki et al., 1992). Several related subunits of the second family have been found (NMDAR2A to NMDAR2D) that, when coexpressed with NMDAR1, form glutamate-gated ion channels, with distinct electrophysiological properties and ligand affinities (Kutsuwada et al., 1992; Monyer et al., 1992; Nakanishi, 1992). Functional diversity in the related family of $\alpha$-amino-3hydroxy-5-methyl-4-isoxazole propionic acid (AMPA)-type glutamate receptors is created by both subunit variety and alternative splicing (Keinänen et al., 1990; Sommer et al., 1990). After the initial cloning of the NMDARI sequence followed several reports of forms of this subunit apparently arising by alternative splicing of a single gene transcript (Anantheram et al., 1992; Durand et al., 1992; Nakanishi et al., 1992; Sugihara et al., 1992; Yamazaki et al., 1992; I Iollmann et al., 1993). These reports described the insertion of a splice cassette into the proposed amino-terminal region of the original NMDAR 1 sequence (termed as the $5^{\prime}$ insertion) and the deletion of two independent consecutive splice cassettes ( $3^{\prime}$ deletions 1 and 2$)$ from the carboxy terminus, the second of which also replaces the original carboxy terminus with a new sequence (see Fig. 1a). These alterations can occur individually or together, since each of the eight possible combinations have been isolated in differing proportions from rat brain (Sugihara et al., 1992; Hollmann et al., 1993). In this study we have followed the terminology of Hollmann et al. (1993), who named the splice variants NMDAR 1-1a, NMDAR 1-1b, NMDAR 1-2a, and so on, where the second number indicates the splice variant at the $3^{\prime}$ end (1 $=$ no deletion; 2,3 , and $4=$ deletions $1,2,1+2$, respectively), and " $a$ " and " $b$ " indicate the absence or presence, respectively, of the 5 ' insertion.

The functional consequences of NMDAR 1 mRNA splicing are as yet incompletely characterized, but results from studies on homomeric channels indicate differences in agonist and antagonist potency, polyamine sensitivity, $\mathrm{Zn}^{2+}$ responses, ethanol sensitivity, and phosphorylation and potentiation by protein kinase C (PKC) activators (Anantheram et al., 1992; Durand et al., 1992; Nakanishi et al., 1992; Sugihara et al., 1992; Yamazaki et al., 1992; Hollmann et al., 1993; Tingley et al., 1993). The members of the NMDAR2 subunit family are differentially expressed in developing and adult rodent brain, in contrast to the total NMDAR 1 mRNA, which is abundantly and ubiquitously expressed (Moriyoshi et al., 1991; Kutsuwada et al., 1992; Monyer et al., 1992; M. Watanabe et al., 1992; H. Monyer, N. Burnashev, D. J. Laurie, B. Sakmann, and P. H. Seeburg, unpublished observations). RNase protection and in situ hybrid- 
a

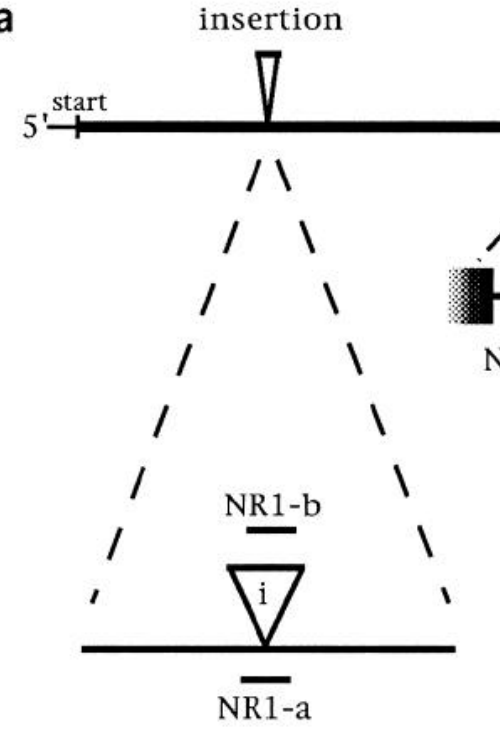

deletions

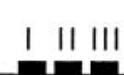
I II |II
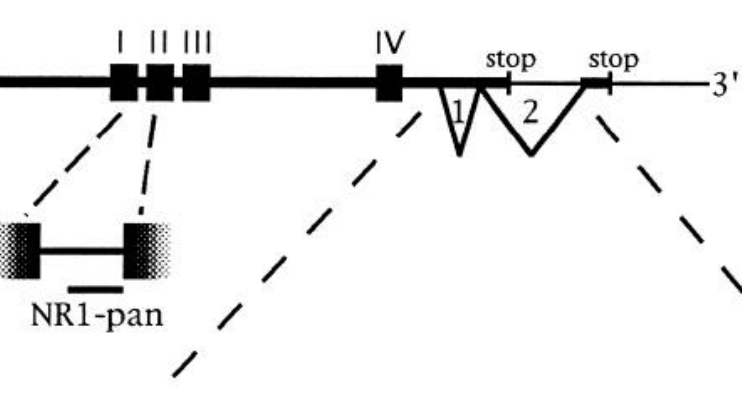

NR1-4

NR1-3

NR1-2

NR1-1

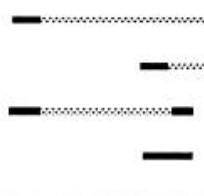

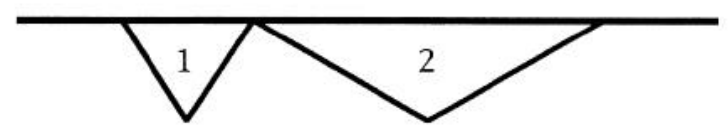

b

\section{NR1 oligonucleotide probe}

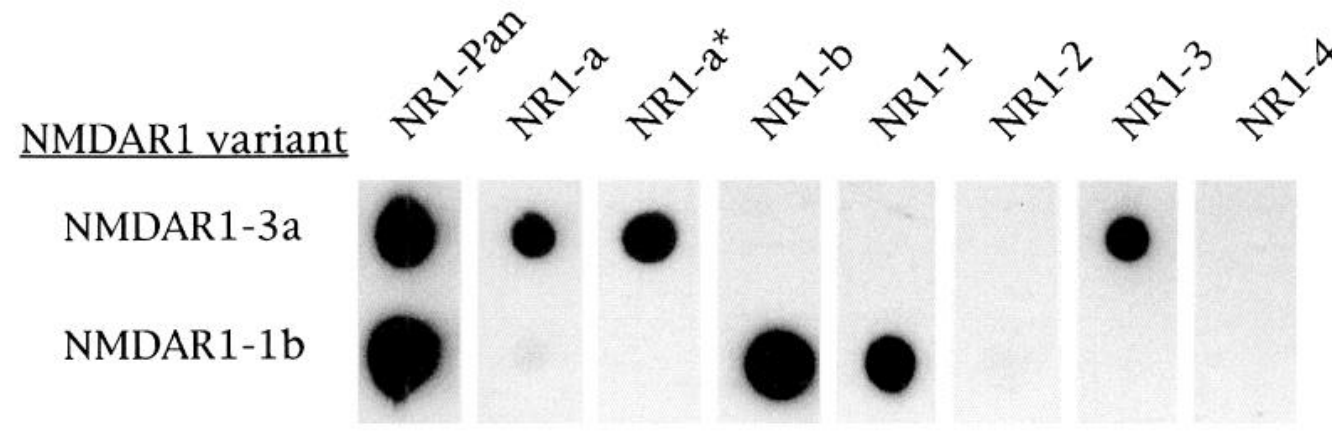

Figure 1. Oligonucleotide probes. $a$, Schematic representation of the NMDAR 1 mRNA, showing transmembrane domains I-IV, the $5^{\prime}$ insertion, $3^{\prime}$ deletions 1 and 2, the start codon, and the two alternative stop codons (Sugihara et al., 1992; Hollmann et al., 1993). The complementary positions of the splice-specific antisense oligonucleotide probes are shown as short solid lines; the stippled lines represent intervening sequences not included in the probes. $b$, Autoradiograph showing the hybridization of ${ }^{32} \mathrm{P} 5^{\prime}$-labeled probes to two specific rat NMDAR1 plasmid DNAs ( $50 \mathrm{fmol}$ each dot) immobilized on nitrocellulose. See Materials and Methods for description of probes. ization analyses have indicated that splicing of the $\mathrm{N}$-terminal cassette is regionally regulated in adult rat brain (Nakanishi et al., 1992; Standaert et al., 1993), suggesting regional heterogeneity in function may exist. Such heterogeneity may also be temporally regulated, giving rise to different splice variant populations and differing responses at various stages of development. By in situ hybridization in developing and adult rat brain with probes specific for the various splice variant mRNAs, we have found that splicing of all three cassettes is both regionally and developmentally regulated.

\section{Materials and Methods}

The experimental procedures employed for in situ hybridization were as described by Wisden et al. (1991), Wisden and Morris (1994), and Laurie and Schrotz (1994). Nonperfused rat brains or whole rat embryos were removed, frozen on dry ice, and sectioned $(14 \mu \mathrm{m})$ on a microtome. Hybridization was performed on sagittal sections of whole embryos of gestational ages 14, 17, and $19 \mathrm{~d}$ (E14, E17, and E19), and on horizontal or sagittal sections of brain from rats of postnatal ages 0,7 , and $12 \mathrm{~d}$
(P0, P7, P12) and adult. Gender was only determined for the adult male rats. Three animals at each developmental stage were examined.

Antisense oligonucleotide probes were 3 ' end labeled to a specific activity of approximately $15 \mu \mathrm{Ci} / \mathrm{pmol}$ using terminal deoxynucleotidyl transferase (Boehringer) and a 30:1 molar ratio of $\alpha{ }^{35} \mathrm{~S}-\mathrm{dATP}(1200 \mathrm{Ci} /$ mmol; New England Nuclear) to probe. The probe recognizing all NMDAR 1 mRNAs (NR1-pan) was the 45 -mer described by Monyer et al. (1992), which hybridizes to the NMDAR 1 mRNA sequence encoding the region between transmembrane domains I and II. The other oligonucleotide probes (40-mers) were designed against specific sequences of the original NMDAR1 clone (Moriyoshi et al., 1991) at the splice sites (Fig. 1a). They were named according to the splice variants to which they would hybridize. For example, NR1-a is complementary to the $5^{\prime}$ splice region in NMDAR $1-1 \mathrm{a},-2 \mathrm{a},-3 \mathrm{a}$ and $-4 \mathrm{a}$ mRNAs, while NR 1-3 recognizes both NMDAR 1-3a and $-3 b$ (see Fig. $1 a$ ). The probe sequences were as follows: NR1-a, AACTGCAGCACCTTCTCTGCCTTGGACTCCCGTTCCTCCA (bases 551-590; Moriyoshi et al., 1991); NR1-b, GCGCTTGTTGTCATAGGACAGTTGGTCGAGGTTTTCATAG (bases 15-54 of insert; Sugihara et al., 1992); NR1-1, TCCACCCCCGGTGCT-CGTGTCTTTGGAGGACCTACGTCTC (bases 2676-2715); NR1-2, TCCACCCCCGGTGCT-CTGCAGGTTCTTCCTCCACACGTTC (bases 2565-2715); NR1-3, GATATCAGTG- 
GGATGGTACTG-CGTGTCTTTGGAGGACCTA (bases 26823077); and NR1-4, GATATCAGTGGGATGGTACTG-CTGCAGGTTCTTCCTCCAC (bases 2574-3077). Dashes indicate where probes span a splice site (see Fig. 1a). The maximum consecutive length of oligonucleotide capable of hybridizing to the wrong splice form was 1925 bases, which under the stringent conditions of hybridization $[50 \%$ formamide, $4 \times$ saline-sodium citrate (SSC), $10 \%$ dextran sulfate, $42^{\circ} \mathrm{C}$, overnight] and washing $\left(1 \times \mathrm{SSC}, 60^{\circ} \mathrm{C}, 20 \mathrm{~min}\right)$ is very unlikely to result in cross-hybridization (Wisden et al, 1991; Wisden and Morris, 1994) (see below). After hybridization and washing, sections were apposed to $\mathrm{x}$-ray film (Kodak X-Omat SB-5) for $10 \mathrm{~d}$, and then dipped in photographic emulsion (Ilford K5) and exposed for 5 weeks. The anatomy of autoradiographs and thionin-stained sections was assessed from the atlases of Paxinos and Watson (1986), Paxinos et al. (1991), and Swanson (1992). Microscopic examination was performed for every structure described. Photomicrographs were obtained using a Zeiss Axioplan microscope under light- and dark-field optics.

Specificity of the hybridization signals was determined in several ways.

(1) Parallel competition experiments, in which excess (200-fold) unlabeled probe was added to the hybridization buffer, resulted in virtually blank autoradiographs (data not shown) except for some nonspecific signals from peripheral tissues such as embryonic liver and thymus (Figs. 2-4) (see Laurie and Schrotz, 1994).

(2) When labeled NR 1-2 or NR 1-4 probes were each incubated with a large excess (200-fold) of the other, unlabeled oligonucleotide only a slight reduction of signal was observed (data not shown). When compared to the result of control (item 1 above), this indicates only very limited cross-hybridization.

(3) Each probe was 5 labeled using $\gamma^{3}{ }^{32} \mathrm{P}$-ATP $(6000 \mathrm{Ci} / \mathrm{mmol}$; New England Nuclear) and polynucleotide kinase to a specific activity of 2.5 $\mu \mathrm{Ci} / \mathrm{pmol}$. Aliquots $(0.05-50 \mathrm{fmol})$ of two plasmid DNAs carrying the NMDAR 1-1b and NMDAR 1-3a splice versions were dotted and immobilized on nitrocellulose membranes, and incubated overnight with each probe. Hybridization and washing conditions were the same as those described above for tissue sections. The washed membranes were exposed to film for $1 \mathrm{hr}$. Each probe was found to hybridize strongly to the appropriate plasmid (Fig. $1 b$ ) with only slight cross-hybridization detected for the NR1-a and NR 1-2 oligonucleotides at the NMDAR1lb dot. In order to reproduce more closely the conditions of the in situ hybridization procedure, $5 \mathrm{pmol}$ of the NR 1 -a probe was $3^{\prime}$ tailed with nonradioactive dATP before being $5^{\prime}$ labeled with ${ }^{32} \mathrm{P}-\mathrm{ATP}$ and hybridized to immobilized plasmids as described above. This probe was termed NR $1-\mathrm{a}^{*}$. Cross-hybridization was considerably further reduced by the presence of the $3^{\prime}$ polyadenosine tail (Fig. $1 b$ ), and was only detectable after an overnight exposure (not shown).

\section{Results}

The changes in signal strength for each splice-specific probe indicate that splicing of the NMDAR 1 mRNA is regulated both regionally and developmentally. All signals reached a peak in the third postnatal week and subsequently declined to adult levels, but each probe exhibited an idiosyncratic hybridization pattern, indicating regional and age-dependent populations of the NMDAR 1 subunit splice variants.

\section{E14}

E14 was chosen as a starting point as this stage is prior to generation, migration, and differentiation of most telencephalic and mesencephalic neurons (Jones 1985; Jacobson, 1991). Hybridization of the NR1-pan probe indicated that the mRNA was expressed weakly throughout the E14 CNS, slightly favoring the colliculi and ventral spinal cord (Fig. 2). Similar, weaker signal patterns were obtained with the other probes except NR I3 , which gave no detectable signal at any examined embryonic stage. Hybridization signals in the embryonic liver and thymus (Figs. 2-4) were also observed in competition controls, and are therefore nonspecific.

\section{E17 and E19}

At these stages the total NMDAR 1 mRNA was detected at a moderate level throughout the brain, with stronger hybridization in the spinal cord, thalamus, and layer I of the developing cortex (Figs. 3, 4). Signals were also observed in dorsal root ganglia, the nasal epithelium, and the trigeminal ganglion. The NR 1-a and NR 1-2 probes produced images similar to that of NR 1-pan (Figs. 3, 4), indicating that the NMDAR 1-2a form predominates at this stage. The strongest signals for NR $1-b$ and NR1-1 in the brain were found in the thalamus, colliculi, and cortical layer I, whereas the NR 1-4 probe hybridized mainly to the tegmentum and pons. All probes except NR 1-3 gave stronger signals in the spinal cord, where a greater variety of splice forms is therefore inferred to exist. Hybridization was greater in ventral spinal cord regions except for the NR1-1 probe. No signal for any probe was detected in the cortical plate.

\section{PO}

The NR1-pan probe showed that at birth total NMDAR $1 \mathrm{mRNA}$ is abundant throughout the brain gray matter, especially in hippocampus and outer layers of the cerebral cortex (Fig. 5). One exception to the ubiquitous strong expression is the globus pallidus, which was not as highly decorated with silver grains. The NMDAR 1-a splice form is similarly distributed at a moderate level, whereas the NMDAR 1-b mRNA is concentrated in the thalamus, sensorimotor cortex, and brainstem. Hybridization patterns of the deletion variant probes began to be more easily discernable than previously. The NR1-2 probe gave a strong, approximately homogeneous signal, similar to that obtained with the NR1-a probe. In contrast, the NMDAR1-1 and NMDAR 1-4 splice variants were more weakly detected, NMDAR 1-1 being concentrated in the cortex, septum, caudate, hippocampus, and anterior thalamus, and NMDAR 1-4 in posterior thalamus, colliculi, and brainstem. The NMDAR 1-3 form was first observed at $\mathrm{PO}$ at a barely detectable level, primarily in cortex and hippocampus. All probes hybridized to the Purkinje cell layer except NR 1-3. The NR 1-pan, NR I -a, and NR 1-1 probes hybridized weakly to the external layer of premigratory granule cells.

\section{P7}

The different patterns of forebrain NMDAR 1 mRNA splicing observed at $\mathrm{P} 0$ became more consolidated by $\mathrm{P} 7$, as the total amount of NMDAR 1 mRNA increased (Fig. 6). Hybridization with the NR 1 -a and NR 1-2 probes indicated that the NMDAR 12a mRNA was predominant and widespread, both probes giving intense signals in hippocampus and olfactory bulb, and strong signals elsewhere, except the globus pallidus. At this age, migratory cortical neurons have reached their final destination (Jacobson, 1991). No marked lamination of the cortical signal was observed, but layers II, III, and V were slightly more intense than the others. NMDAR 1-b mRNA was much more restricted, with hybridization highlighting some thalamic nuclei, olfactory bulb, lateral striatum, CA3 of the hippocampus, inferior colliculi, brainstem, and layers III and V of the sensorimotor and parietal cerebral cortices. Unlike the NR1-2 signal, which was strong throughout the forebrain, that of NR $1-1$ was principally in more peripheral structures such as cortex, striatum, hippocampus, dorsal septum, and olfactory bulb, while that of NR 1-4 was concentrated in deeper structures like ventral septum, thalamus, colliculi, brainstem, and hippocampal CA3 field, in ad- 

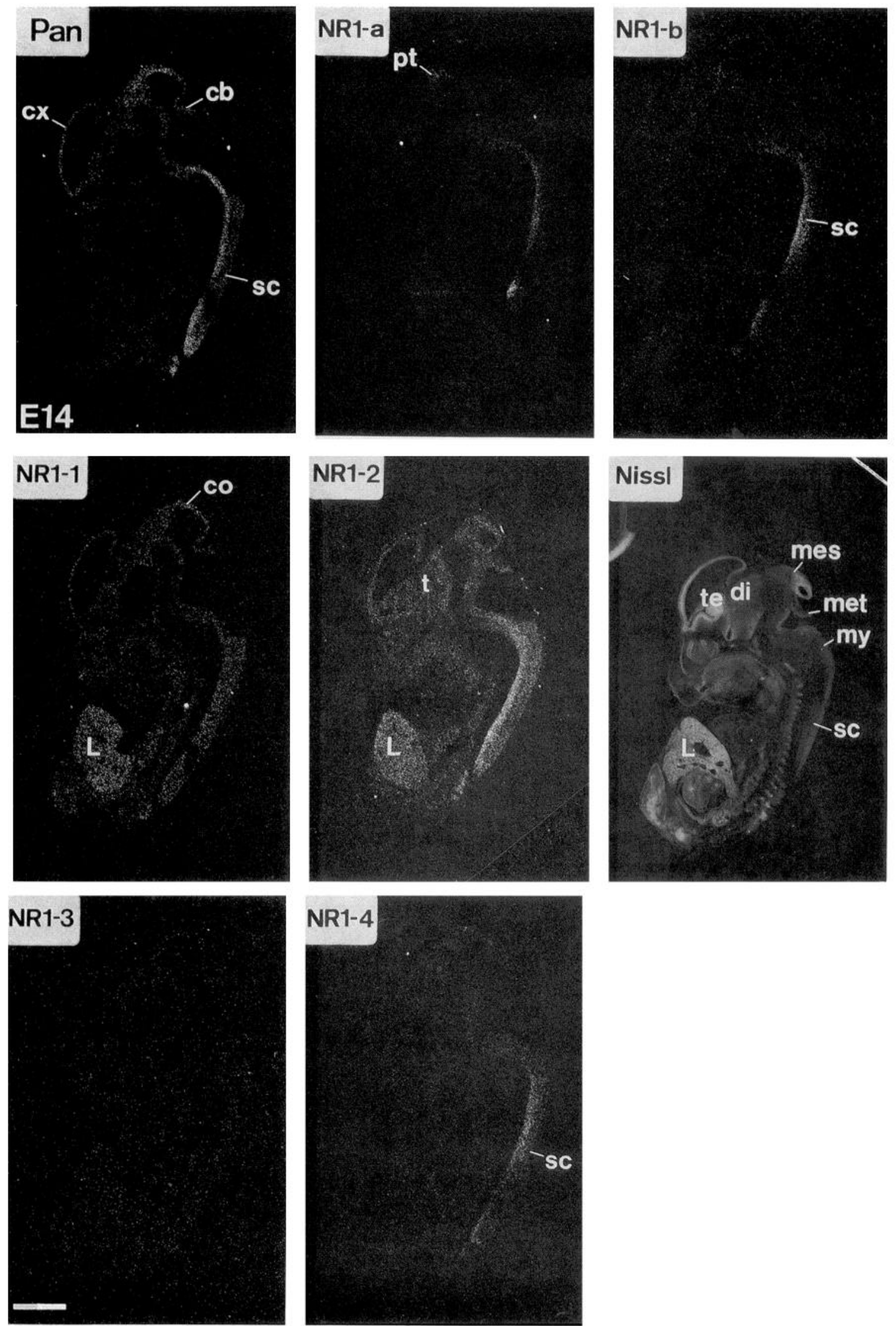

Figure 2. X-Ray film autoradiographs depicting the in situ hybridization of the NMDAR1 splice variant probes to sagittal sections of E14 rat embryos. Pan, NR1-pan; Nissl, Nissl stain. For abbreviations, see Appendix. Scale bar, 2 mm. 

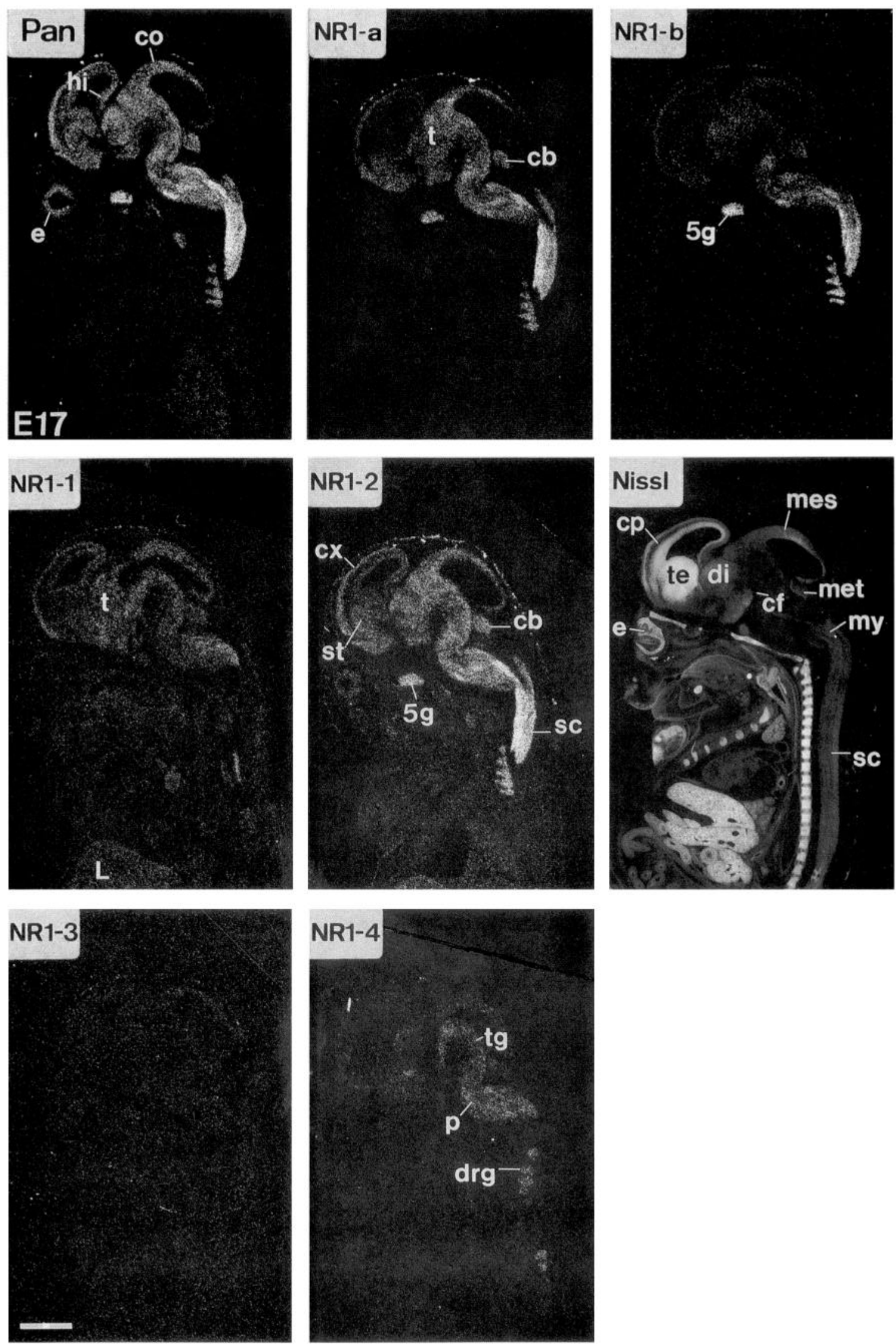

Figure 3. X-Ray film autoradiographs depicting the in situ hybridization of the NMDARI splice variant probes to sagittal sections of E17 rat embryos. Pan, NR1-pan; Nissl, Nissl stain. For abbreviations, see Appendix. Scale bar, $2 \mathrm{~mm}$. 

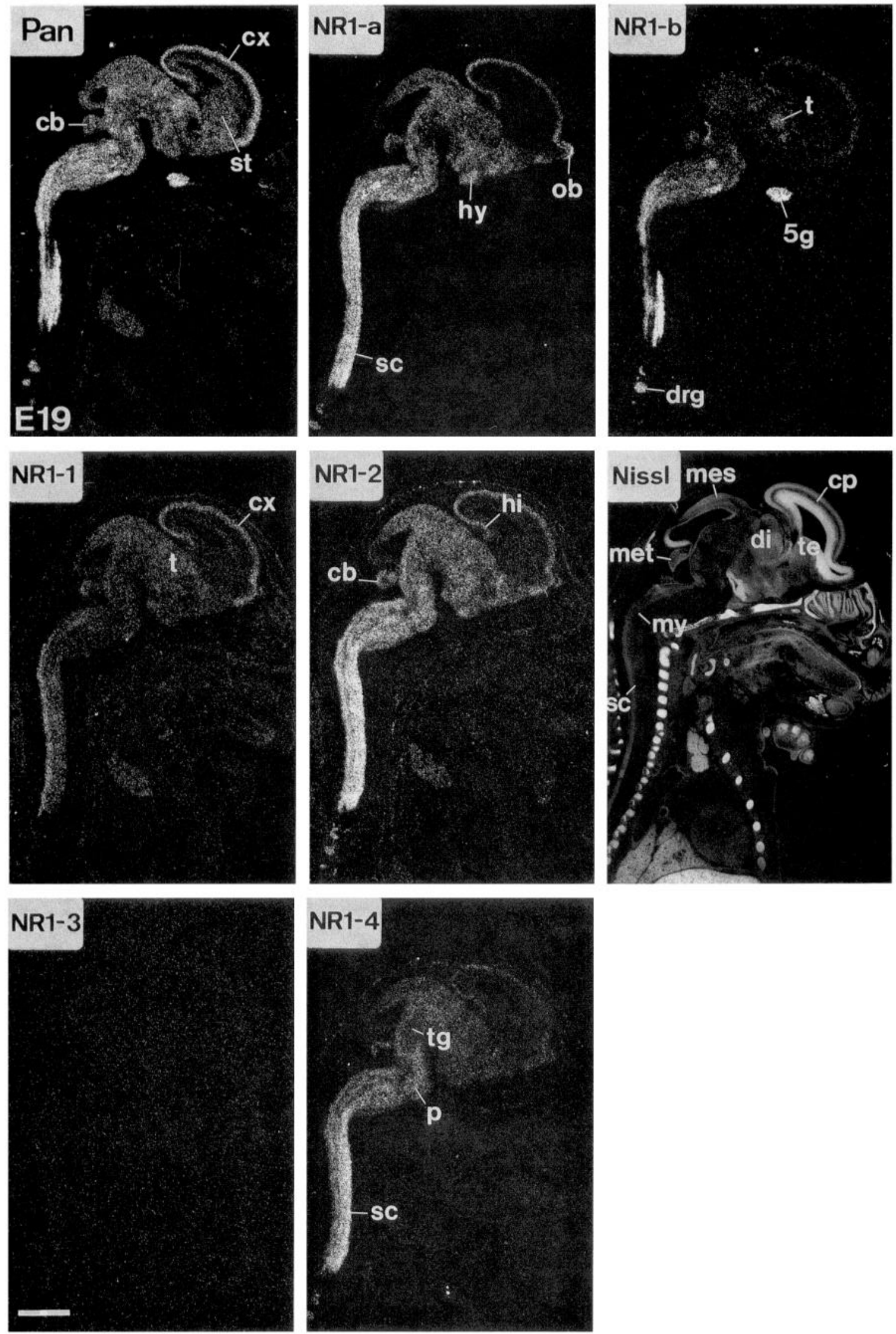

Figure 4. X-Ray film autoradiographs depicting the in situ hybridization of the NMDAR1 splice variant probes to sagittal sections of E19 rat embryos. Pan, NR1-pan; Nissl, Nissl stain. For abbreviations, see Appendix. Scale bar, $2 \mathrm{~mm}$. 

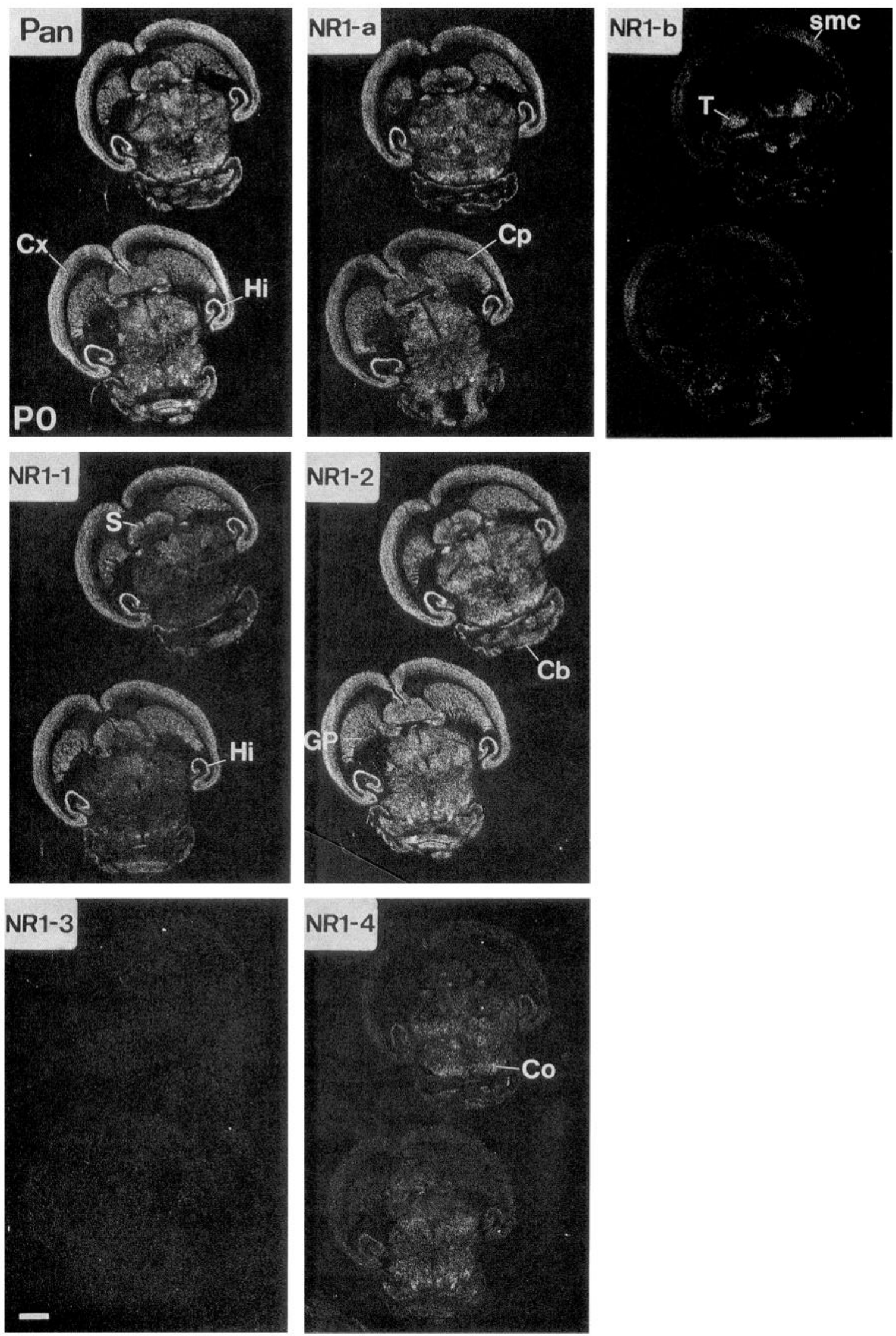

Figure 5. X-Ray film autoradiographs depicting the in situ hybridization of the NMDAR1 splice variant probes to horizontal sections of P0 rat brain. Pan, NR1-pan. For abbreviations, see Appendix. Scale bar, $1.8 \mathrm{~mm}$. 

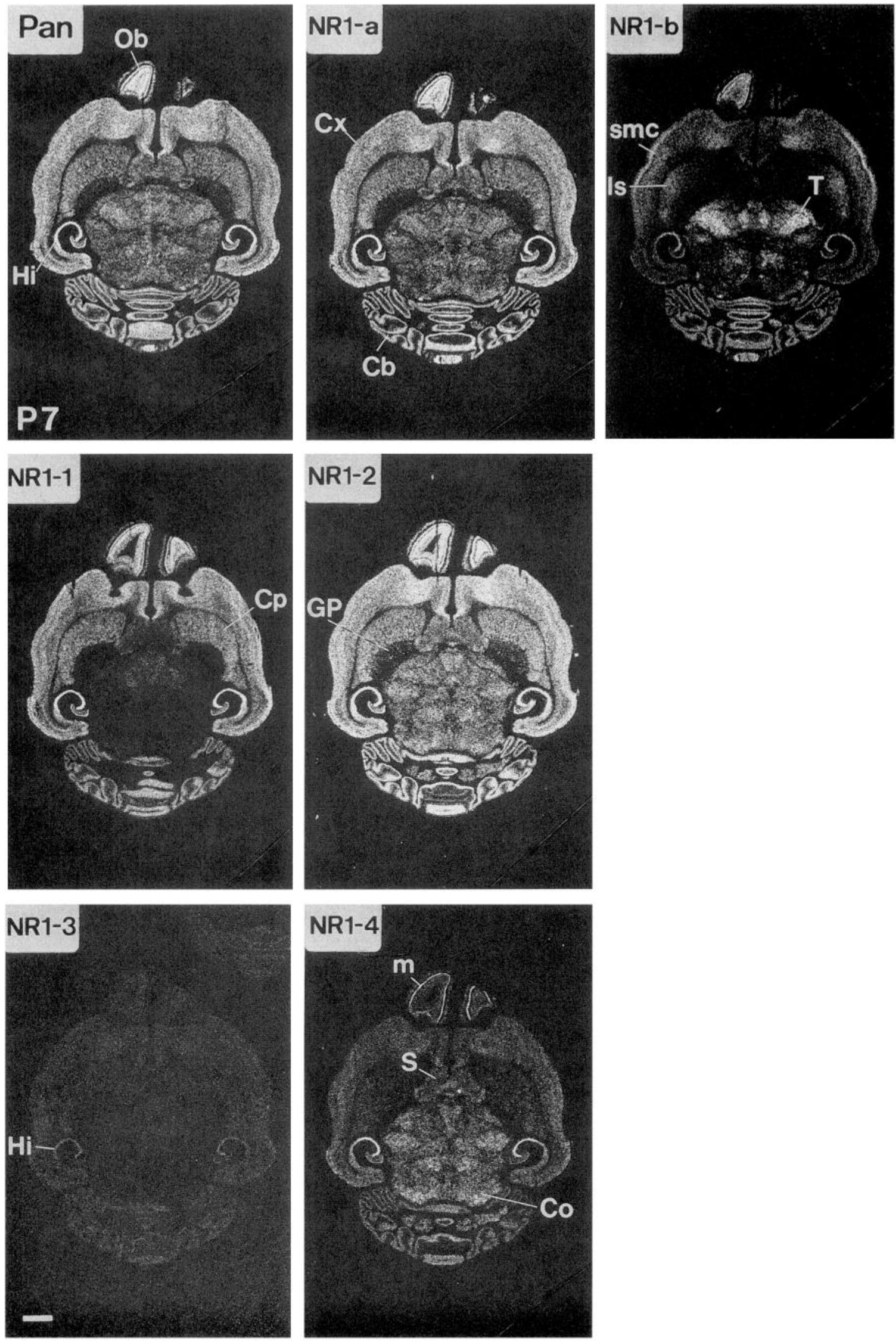

Figure 6. X-Ray film autoradiographs depicting the in situ hybridization of the NMDAR1 splice variant probes to horizontal sections of P7 rat brain. Pan, NR1-pan. For abbreviations, see Appendix. Scale bar, $1.8 \mathrm{~mm}$. 
dition to mitral cells of the olfactory bulb. Only a minor proportion of the forebrain NMDAR $1 \mathrm{mRNA}$ at P7 was present as the NMDAR 1-3 splice form, the NR1-3 probe giving a very weak signal in cortex, thalamus, and hippocampus. In the cerebellum, the NR1-pan, -a, and -2 probes each strongly labeled both postmigratory granule cells and Purkinje cells, while NR 1-b labeled both moderately, and NR 1-3 weakly labeled only granule cells. Although both NR1-1 and NR1-4 probes hybridized to both cell types, the first probe principally labeled granule cells and the second Purkinje cells. Weak hybridization to migrating and immediatcly premigratory granule cells was observed for all probes except NR1-3 and NR1-4.

\section{P12}

All probes gave their strongest hybridization signals at P12. This study did not address the stage of peak expression for each splice form, but we have found from in situ hybridization data (D. J. Laurie and P. H. Seeburg, unpublished observations) that the peak of NMDAR 1 mRNA expression, and of splicing within the N-terminal coding sequences, occurs between P14 and P20. For each splice-specific probe, patterns of hybridization were regionally very similar to that described above for $\mathbf{P 7}$, despite the increase in abundance. However, the relatively larger increases in NMDAR l-b, - 1, -3, and -4 mRNA abundance indicate that these splice forms begin to account for a greater proportion of NMDAR 1 mRNA in forebrain and cerebellum than previously (Fig. 7).

\section{Adult}

After the third postnatal week, the strength of all hybridization signals declined, although the different regional patterns of NMDAR $1 \mathrm{mRNA}$ splicing were fundamentally preserved (Figs. 8, 9). As has been described before (Moriyoshi et al., 1991; Monyer et al., 1992), the NMDAR 1 mRNA was abundant in every adult neuronal type examined. Most of this mRNA was of the NMDAR1-a type, except in certain areas such as sensorimotor cortex, thalamus, hippocampal CA3 field, colliculi, olfactory bulb, pontine nuclei, and brainstem, where a considerable proportion of NMDAR 1 mRNA contained the 5 ' insertion. Differential splicing of this site was also observed in the cerebellum where the NMDAR 1-a form predominated in Purkinje cells, and the NMDAR 1-b form in stellate-basket cells and granule cells (Figs. 8-10), compared to the overall predominance of the NMDAR 1-a type at earlier (P7) stages (Fig. 6). All Purkinje cells were lightly labeled by the NR 1-b probe (Fig. 10). In contrast to the neonatal brain, where the NMDAR 1-2 variant predominated considerably, an estimated half of adult brain NMDAR 1 mRNA was of this form and was homogeneously expressed. The remainder appeared to comprise the NMDAR 1-1 and -4 forms in almost complementary distributions, with the NMDAR 1-1 form concentrated in rostral structures (e.g., olfactory bulb, cortex, caudate, hippocampus) and the NMDAR 1-4 variant primarily in caudal areas (hippocampus, thalamus, colliculi, cerebellum, brainstem) (Figs. 8, 9). In further contrast to earlier (e.g., P7) stages, the NMDAR 1 - 1 variant was only weakly detected in adult cerebellar granule cells, whereas moderate amounts of the NMDAR 1-4 form were found in both Purkinje and granule cell types. The NR1-3 variant was, again, barely detectable in adult cortex and hippocampus. Hybridization signals from each probe except NR 1-3 were unexpectedly detected over some cells in cortical layer I, which were presumably glia (Jacobson, 1991), but not over glial cells in brain white matter tracts.

\section{Discussion}

From this in situ hybridization study on developing rat brain we have observed that the primary NMDAR 1 gene transcript is spliced at both $5^{\prime}$ and $3^{\prime}$ sequences in a regionally differential manner, and that these regional patterns of splicing do not greatly change between birth and adulthood, despite considerable changes in overall abundance. The caudal-to-rostral gradient in the appearance of embryonic NMDAR $1 \mathrm{mRNA}$, the early postnatal peak and the ubiquitous, high neuronal adult expression levels concur with other studies on total NMDAR 1 mRNA in developing and adult rodent brain (Moriyoshi et al., 1992; M. Watanabe et al., 1992). Similarly, the adult brain distribution of the NMDAR1-b mRNA form (Figs. 8-10) agrees very well with that described by recent in situ hybridization and RNase protection studies (Nakanishi et al., 1992; Standaert et al., 1993). The drop in the NR1-pan signal observed between P12 and adult is probably a consequence of both normal neuronal death (Oppenheim, 1991) and a reduction in expression by each neuron, since the grain clusters over individual neurons were much denser at P12 than at maturity (not shown).

The different patterns of hybridization to brain sections (Figs. 2-10) and to known NMDARl variants on nitrocellulose (Fig. $1 b$ ) indicate that each 40-mer probe recognized a specific splice variant despite cross-identity of up to 25 consecutive nucleotides (Fig. 1a). It would be expected that the total signals obtained by combining the NR1-a and -b images, or the NR1-1, $-2,-3$, and -4 images should be equivalent to that obtained with the NR 1-pan probe. Allowing for factors such as the lower specific activity of the NR1-pan probe (approximately two-thirds of the others to avoid overprinting) and its slightly greater length, the NR1-pan signal does appear to be approximately the sum of each subgroup. The ratios of the NMDAR $1-a$ and $-b$ mRNA splice forms in adult rat forebrain and cerebellum, previously suggested to be about 5:1 and 1:5, respectively (Anantharam et al., 1992; Nakanishi et al., 1992; Sugihara et al., 1992), concur with visual estimates from the present in situ hybridization figures (Figs. 8, 9). However, there is less consensus over the relative amounts of the 3 ' splice forms NMDAR $1-1,-2,-3$, and -4 in forebrain; ratios of 1.5:1:x:x and 9:1:0.8:0.8 have been proposed [Anantharam et al., 1992 ( $\mathrm{x}=$ not reported); Sugihara et al., 1992]. Visual assessment of the present results implies relative amounts with the order NMDAR $1-2>-1>-4 \gg-3$ (Figs. 8, 9). The different ratios may be due to the different methods employed (semiquantitative PCR, library screening).

\section{Regional populations}

Examination of the hybridization patterns reveals similarity between the images obtained using the NR $1-b$ and -4 probes (Figs. $8,9)$. The NR 1 -a and -1 probes also yielded largely overlapping hybridization patterns (Figs. 8,9). These results, together with the widespread signals obtained with the NR 1-2 probe, indicate that the NMDAR $1-1 \mathrm{a}$ and $-2 \mathrm{a}$ forms may frequently occur in cortex, caudate, and hippocampus, and the NMDAR $1-2 b$ and $-4 b$ forms in thalamus, colliculi, cerebellum, and brainstem. However, there exists considerable overlap between all splice variant images, so it will require other approaches (e.g., regional library screening, splice variant-specific antibodies) to ascertain regional populations. Use of such antibodies would also be useful in determining the cellular location of the splice forms. The different patterns of NMDAR 1 mRNA splice forms are fundamentally constant throughout postnatal development, indications of future heterogeneity even being apparent as early as 

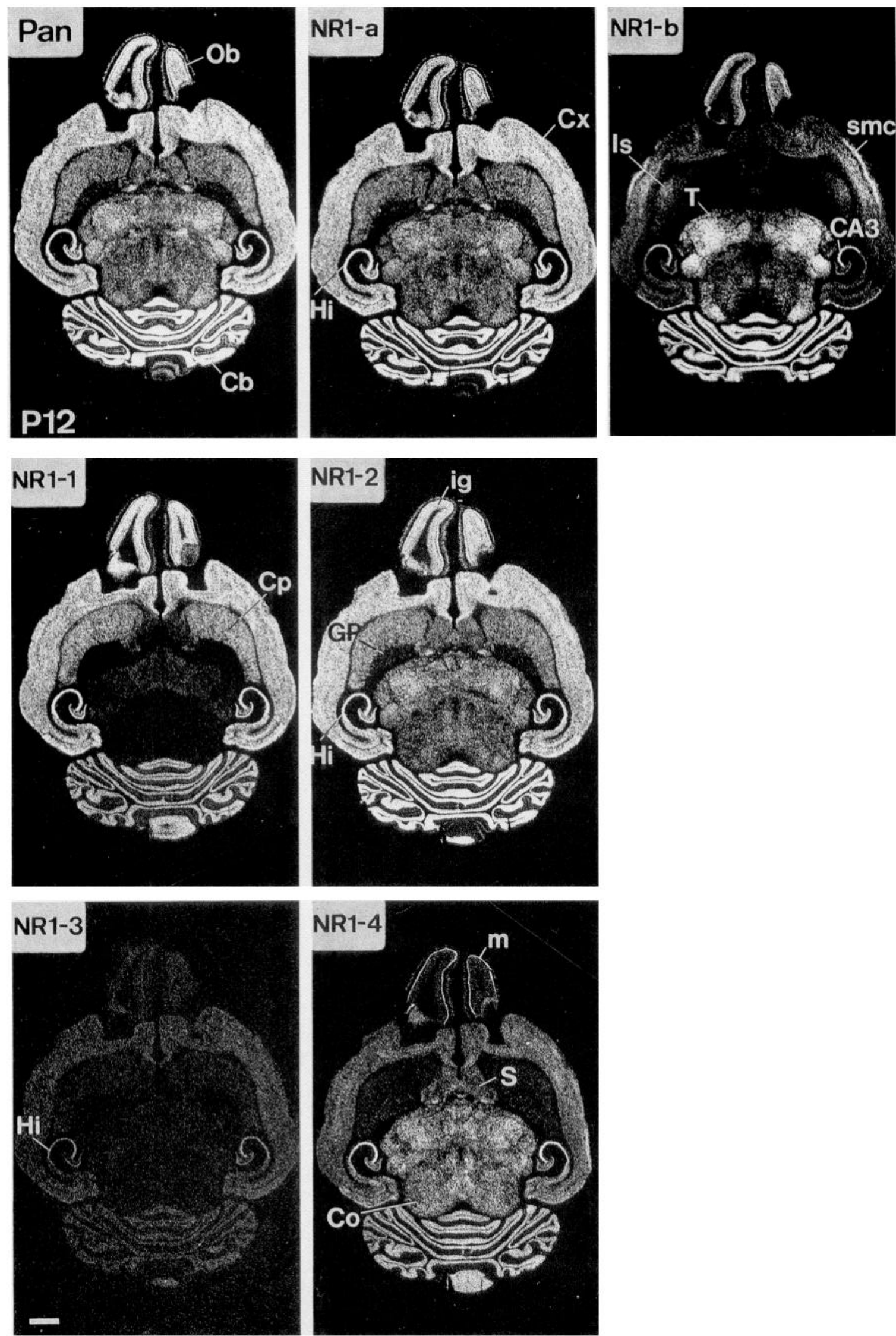

Figure 7. X-Ray film autoradiographs depicting the in situ hybridization of the NMDAR1 splice variant probes to horizontal sections of P12 rat brain. Pan, NR1-pan. For abbreviations, see Appendix. Scale bar, $1.8 \mathrm{~mm}$. 

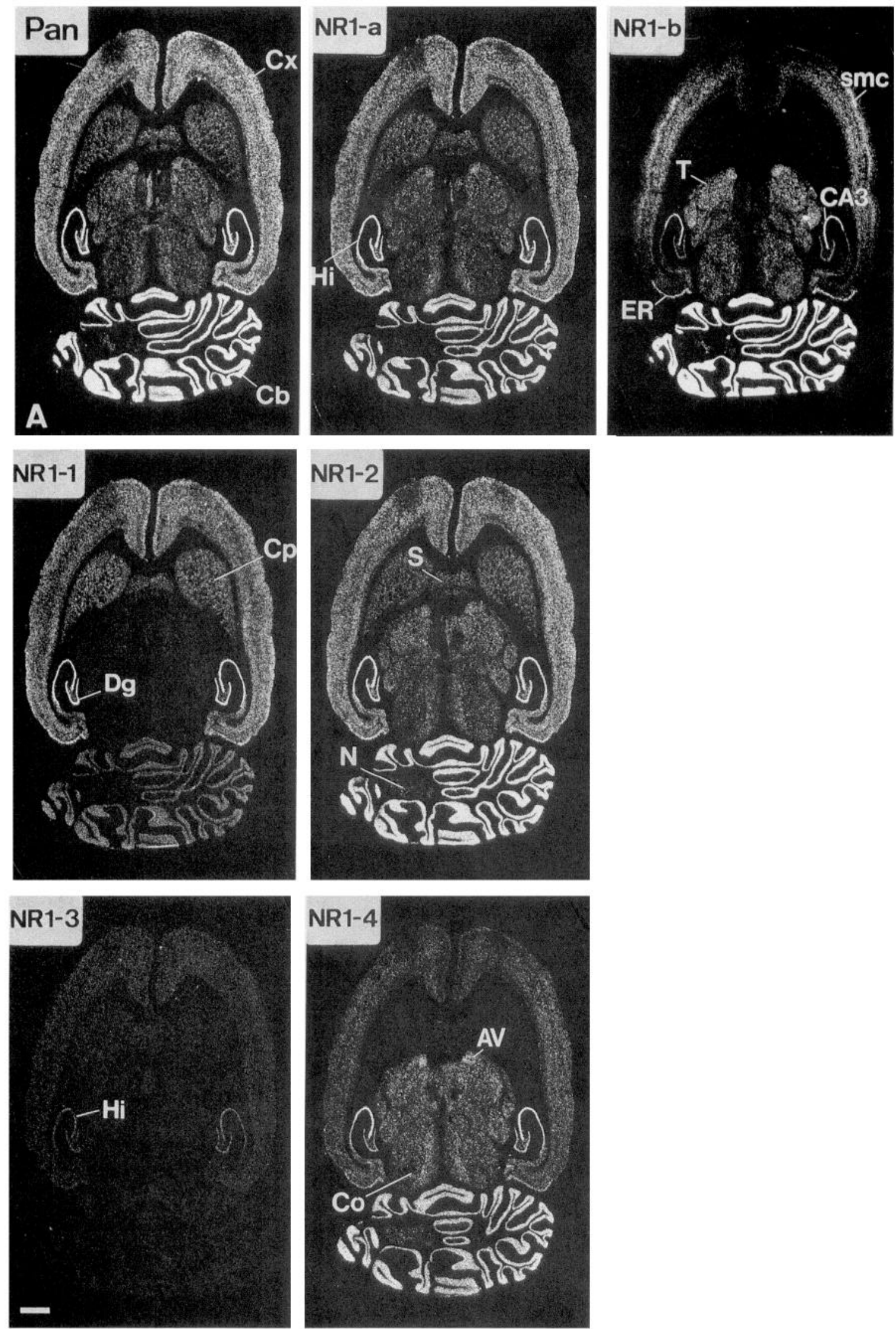

Figure 8. X-Ray film autoradiographs depicting the in situ hybridization of the NMDAR1 splice variant probes to horizontal sections of adult rat brain. Pan, NR1-pan. For abbreviations, see Appendix. Scale bar, $1.8 \mathrm{~mm}$. 

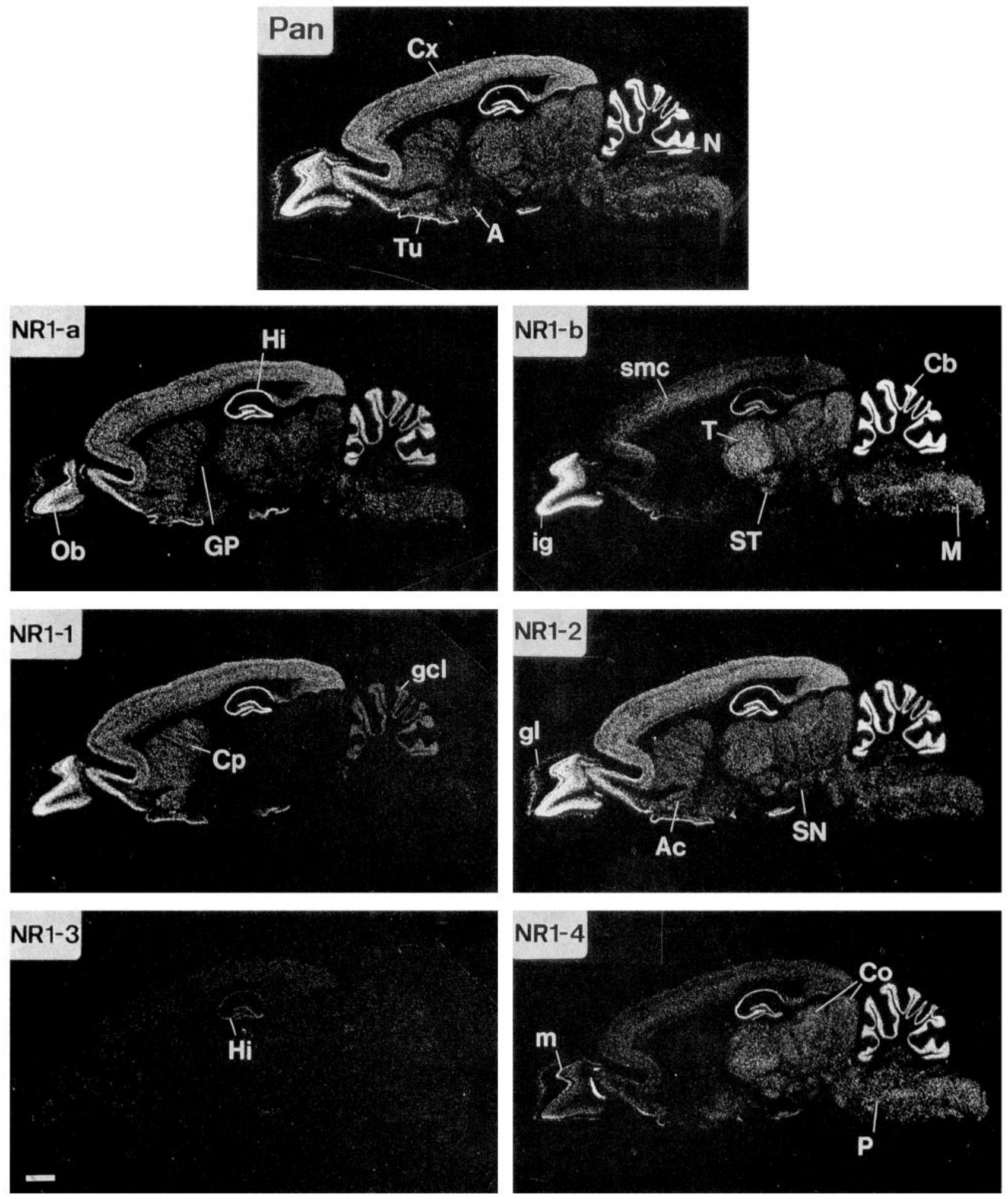

Figure 9. X-Ray film autoradiographs depicting the in situ hybridization of the NMDAR1 splice variant probes to sagittal sections of adult rat brain. Pan, NR1-pan. For abbreviations, see Appendix. Scale bar, $1.8 \mathrm{~mm}$.

E17 and E19 (Figs. 3, 4). The most noticeable changes are the relatively greater proportion of NMDAR $1-1$ and -4 forms in mature, compared to perinatal, forebrain, and the change of dominant splice forms in the cerebellar granule cells (Figs. 510 ), which mature relatively late in development (Jacobson,
1991). Thus, throughout the postnatal development of each brain structure, similar populations of splice forms exist, each reaching a peak of abundance in the third postnatal week (Figs. 68 ). This peak, together with the concurrent peaks of expression of NMDAR2 subunit mRNAs (M. Watanabe et al., 1992; Mon- 


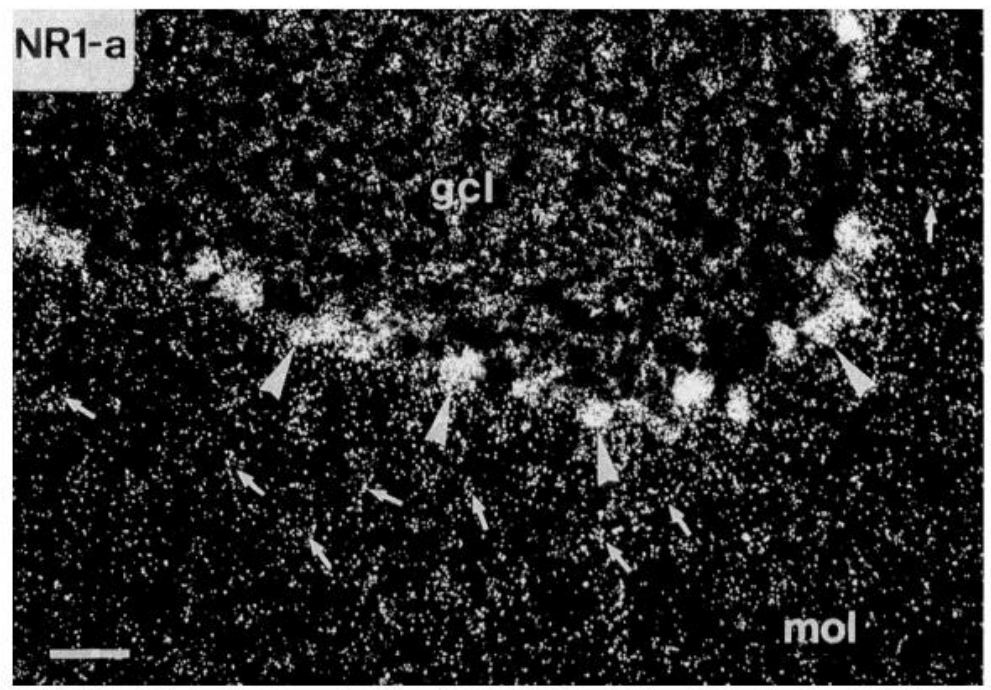

Figure 10. Dark-field photomicrographs depicting the in situ hybridization of two NMDAR 1 splice variant probes $(N R I-a$ and $-b)$ to sagittal sections of adult rat cerebellum. Arrowheads indicate Purkinje cells; arrows indicate stellate-basket cells. For abbreviations, see Appendix. Scale bar, $50 \mu \mathrm{m}$.

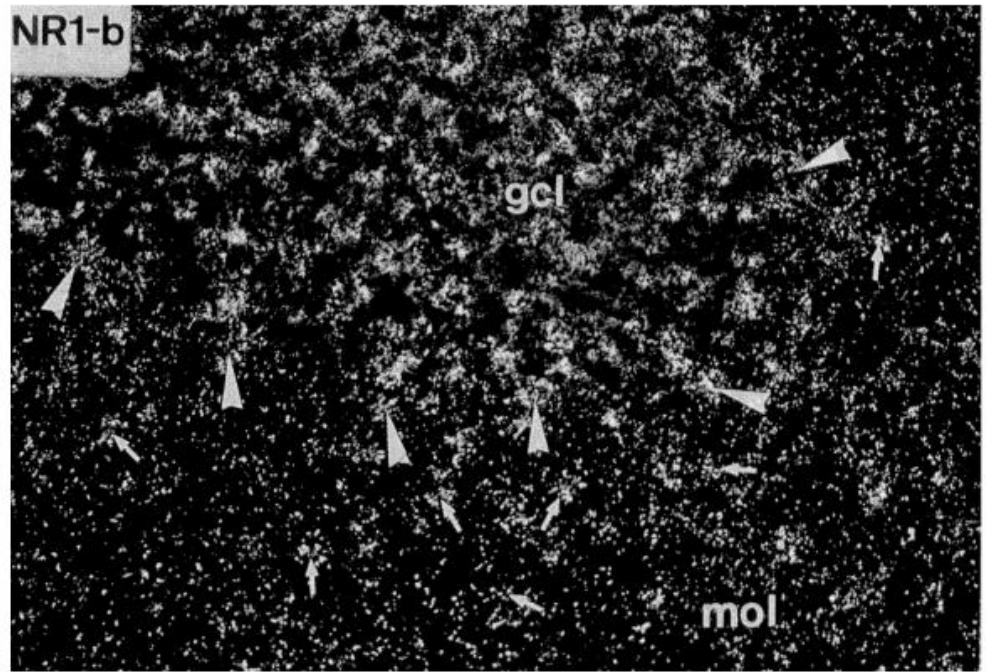

yer, Burnashev, Laurie, Sakmann, and Seeburg, unpublished observations), coincides with the most active period of mature synapse formation (Aghajanian and Bloom, 1967). The inferred abundance and regional variety of NMDA receptors, consisting of different NMDAR1 splice variants and NMDAR2 subunits, would probably play an important role in regionally heterogeneous synaptic plasticity, synapse consolidation, and perhaps the subsequent elimination of excess neurons (McDonald and Johnston, 1990; Jacobson, 1991). Similar populations of splice forms appear to be retained at a lesser degree in structures of the mature brain, perhaps serving the same purpose of regionally heterogeneous synaptic plasticity (Collingridge and Singer, 1990). In the hippocampus, for example, the differential distribution of the NMDAR 1-b and -4 variants, contrasting with the even signals using the other splice-specific probes (Figs. 8, 9), implies intrahippocampal heterogeneity of NMDAR1 splice variant populations. This molecular heterogeneity may be of physiological importance in the differences known to exist between Schaeffer collateral (CA1) and mossy fiber (CA3) types of synaptic potentiation (Staubli, 1992; Y. Watanabe et al., 1992; Zalutsky and Nicoll, 1992), or of pathological importance in the different sensitivities of the CA1 and CA3 regions to ischemic glutamate excitotoxicity (Mitani et al., 1992). Differential al- ternative splicing of the 5 ' sequence of NMDAR 1 mRNA often occurs in motion-associated structures (caudate (NMDAR1-a $\gg$ NMDAR1-b), P12 lateral caudate $(\mathrm{a}=\mathrm{b})$, sensorimotor cortex $(a=b)$, thalamus $(b>a)$, subthalamic nuclei $(b>a)$, substantia nigra $(\mathrm{a} \gg \mathrm{b})$, cerebellar Purkinje cells $(\mathrm{a}>\mathrm{b})$, cerebellar granule cells $(b>a)$ (Figs. 7-10), suggesting that the two forms may have important physiological and perhaps pathological roles in motor coordination.

\section{Functional heterogeneity}

Some electrophysiological properties of the eight known NMDAR1 splice forms have been examined in oocytes by various groups. A consensus of the data indicates that relative to the NMDAR 1-a variant, NMDAR 1-b homomeric channels give greater maximum currents, and possess lower affinity for agonists but greater affinity for antagonists (both two- to fourfold) (Durand et al., 1992; Nakanishi et al., 1992; Sugihara et al., 1992; Hollmann et al., 1993). These different ligand affinities have been proposed (Hollmann et al., 1993) as a possible basis for the heterogeneity of NMDA receptor glutamate binding sites found in rat brain (Monaghan et al., 1988). However, the affinity differences of the recombinant NMDAR $1-a$ and -b homomeric assemblies for NMDA receptor antagonists are much smaller 
than those differences observed in brain (20-50-fold) (Murphy et al., 1988; Sills et al., 1991). Additionally, although the NR1$\mathrm{la}$ and $-\mathrm{b}$ in situ hybridization images (Figs. 8,9) are somewhat similar to the distribution of agonist- and antagonist-preferring binding sites, respectively (Monaghan et al., 1988; Monaghan, 1991; Monaghan and Beaton, 1992), there is considerable overlap of expression of the splice variants (Figs. 8,9) and insufficient correlation with the ligand autoradiography to infer that the NMDAR 1 5' splice variant defines the ligand affinity. Recent experiments on recombinant heteromeric NMDAR1/NMDAR2 receptors show that large differences in agonist and antagonist affinity can be reproduced by changing the NMDAR2 subunit (Laurie and Seeburg, unpublished observations, D. T. Monaghan, personal communication). Moreover, the mRNA distributions for the NMDAR2 subunits (Kutsuwada et al., 1992; Monyer et al., 1992; Ishii et al., 1993) closely correlate to the distributions of the appropriate NMDA binding sites (Monaghan et al., 1988; Monaghan, 1991; Monaghan and Beaton, 1992). Whether alternative 5 ' splice forms of the NMDAR 1 mRNA in heteromeric recombinant NMDAR1/NMDAR2 assemblies can modulate ligand affinity, affect polyamine responses (Durand et al., 1992), or influence voltage dependency (Anantharam et al., 1992) remains to be tested.

Low concentrations of $\mathrm{Zn}^{2+}$ ions potentiate glutamate-gated currents at homomeric NMDAR 1-a assemblies, but higher concentrations are inhibitory at both NMDAR $1-a$ and - $b$ homomeric receptors (Hollmann et al., 1993). The different distributions of NMDAR 1-a and -b mRNAs (Figs. 8-10; Standaert et al., 1993) may not lead to regional heterogeneity in $\mathrm{Zn}^{2+}$ responses, however. Coexpression of NMDAR $1-\mathrm{a}$ and $-\mathrm{b}$ mRNA, a likely situation since NMDAR 1-a mRNA seems to be present in every neuronal type, results in assemblies possessing only NMDAR 1-a-like $\mathrm{Zn}^{2+}$ sensitivities (Hollmann et al., 1993). Moreover, the $\mathrm{Zn}^{2+}$ potentiation is lost in heteromeric NMDAR 1-a/NMDAR2 assemblies (Hollmann et al., 1993), which is probably the dominant composition of cerebral NMDA receptors (Kutsuwada et al., 1992; Monyer et al., 1992; Ishii et al., 1993). Thus, the potentiation by $\mathrm{Zn}^{2+}$ may not occur, unless homomeric NMDAR 1-a channels are formed by specific controlled assembly and/or by the absence of NMDAR2 subunits, such as appears to occur in adult cerebellar Purkinje cells (Kutsuwada et al., 1992; Monyer et al., 1992; Ishii et al., 1993), which also contain much more NMDAR 1-a than -b mRNA (Fig. 10). The absence of NMDAR2 subunit mRNAs in adult cerebellar Purkinje cells, allowing only the production of poorly conducting homomeric NMDAR 1 channels (Moriyoshi et al., 1991), may account for the lack of detectable NMDA-gated responses on these cells (Audinat et al., 1990; Hirano, 1990; Perkel et al., 1990; Farrant and Cull-Candy, 1991; Hussain et al., 1991).

Alternative splicing of the $3^{\prime}$ sequences of NMDAR 1 mRNA does not appear to affect ligand affinities, responses to $\mathrm{Zn}^{2+}$ or polyamines, or sensitivity to $\mathrm{Mg}^{2+}$ inhibition (Durand et al., 1992; Nakanishi et al., 1992; Sugihara et al., 1992; Yamazaki et al., 1992; Hollmann et al., 1993). Recently, recombinant homomeric NMDAR 1-1a receptors were shown to be phosphorylated at the carboxy terminus to a much greater degree under baseline and experimental conditions than NMDAR 1-2a assemblies, which hints to the carboxy terminus of the NMDAR 1 subunit being located intracellularly (Tingley et al., 1993), in contrast to the extracellular location originally proposed (Moriyoshi et al., 1991). Use of consensus phosphorylation sites within the deletion cassettes, and their removal by alternative splicing, may regulate channel properties such as desensitization (Huganir and Greengard, 1990), or the induction of LTP by PKC (Ben-Ari et al., 1992). Indeed, NMDA-gated currents at recombinant homomeric NMDAR 1-3b channels are much more sensitive to potentiation by $\mathrm{PKC}$ activators than those at NMDAR 1-1a assemblies (Durand et al., 1992; Yamazaki et al., 1992), although receptors containing the NMDAR 1-3b subunit are probably very scarce throughout development (Figs. 2-9). Regional and developmental regulation of splicing of the $3^{\prime}$ sequences of NMDAR $1 \mathrm{mRNA}$, exemplified by the contrasting distributions of NMDAR 1-1 and NMDAR 1-4 mRNAs (Figs. 5-9), may control sensitivities to phosplior ylation and therefore kinetic properties of the NMDA channels and their involvement in LTP and synaptic plasticity.

In conclusion, we have found that NMDAR 1 mRNA expression develops in a caudal to rostral gradient, that markedly different but overlapping patterns of $5^{\prime}$ and $3^{\prime}$ splicing appear by birth, and that this regional heterogeneity is extensively maintained through the postnatal expression peak and subsequent decline to adult expression levels. Determination of the functional consequences of the regionally specific splicing is an intriguing prospect.

\section{Appendix}

\section{List of abbreviations}

$5 \mathrm{~g}$ embryonic trigeminal ganglion

A amygdala

Ac nucleus accumbens

AV anteroventral thalamic nuclei

CA3 hippocampal CA3 region

$\mathrm{Cb}$ cerebellum

$\mathrm{cb}$ embryonic cerebellum

cf cephalic flexure

Co colliculi

co embryonic colliculi

Cp caudate-putamen

cp cortical plate

$\mathrm{Cx} \quad$ cortex

cx embryonic cortex

$\mathrm{Dg}$ dentate gyrus

di embryonic diencephalon

drg embryonic dorsal root ganglion

e embryonic nasal epithelium

ER entorhinal cortex

gcl cerebellar granule cell layer

gl glomerular layer

GP globus pallidus

$\mathrm{Hi}$ hippocampus

hi embryonic hippocampus

hy embryonic hypothalamus

ig internal granule cell layer

L embryonic liver

ls lateral striatum

M medulla

m mitral cell layer

mes embryonic mesencephalon

met embryonic metencephalon

$\mathrm{mol} \quad$ cerebellar molecular layer

my embryonic myelencephalon

$\mathrm{N}$ deep cerebellar nucleus

$\mathrm{Ob} \quad$ olfactory bulb

ob embryonic olfactory bulb

$\mathrm{P}$ pons

p embryonic pons

pt embryonic pretectum

S septum

sc embryonic spinal cord

smc sensorimotor cortex

SN substantia nigra 
ST subthalamic nucleus

st embryonic striatum

$\mathrm{T}$ thalamus

$\mathrm{t}$ embryonic thalamus

te embryonic telencephalon

tg embryonic tegmentum

Tu olfactory tubercle

\section{References}

Aghajanian GK, Bloom FE 1967) The formation of synaptic junctions in developing rat brain: a quantitative electron microscopic study. Brain Res 6:716-727.

Anantharam V, Panchal RG, Wilson A, Koltchine VV, Treistman SN, Bayley H (1992) Combinatorial RNA splicing alters the surface charge on the NMDA receptor. FEBS Lett 305:27-30.

Audinat E, Knopfel T, Gahwiler BH (1990) Responses to excitatory amino acids of Purkinje cells and neurones of the deep nuclei in cerebellar slice cultures. J Physiol (Lond) 430:297-313.

Ben-Ari Y, Aniksztejn L, Bregestovski P (1992) Protein kinase C modulation of NMDA currents: an important link for LTP induction. Trends Neurosci 15:333-339.

Collingridge GL, Singer W (1990) Excitatory amino acid receptors and synaptic plasticity. Trends Pharmacol Sci 11:290-296.

Durand GM, Gregor P, Zheng X, Bennett MVL, Uhl GR, Zukin RS (1992) Cloning of an apparent splice variant of the rat $N$-methyl-Daspartate receptor NMDAR 1 with altered sensitivity to polyamines and activators of protein kinase C. Proc Natl Acad Sci USA 89:93599363.

Farrant M, Cull-Candy SG (1991) Excitatory amino acid receptorchannels in Purkinje cells in thin cerebellar slices. Proc R Soc Lond [Biol]. 244:179-184.

Hirano $T$ (1990) Synaptic transmission between rat inferior olivary neurons and cerebellar Purkinje cells in culture. J Neurophysiol 63: 181-189.

Hollmann M, Boulter J, Maron C, Beasley L, Sullivan J, Pecht G, Ileinemann S (1993) Zinc potentiates agonist-induced currents at certain splice variants of the NMDA receptor. Neuron 10:943-954.

Huganir RL, Greengard P (1990) Regulation of receptor desensitization by protein phosphorylation. Neuron 5:555-567.

Hussain S, Gardner CR, Bagust J, Walker RJ (1991) Receptor subtypes involved in responses of Purkinje cells to exogenous excitatory amino acids and local electrical stimulation in cerebellar slices in the rat. Neuropharmacology 30:1029-1037.

Ishii T, Moriyoshi K, Sugihara H, Sakurada K, Kadotani H, Yokoi M, Akazawa C, Shigemoto R, Mizuno N, Masu M, Nakanishi S (1993) Molecular characterization of the family of the $N$-methyl-D-aspartate receptor subunits. J Biol Chem 268:2836-2843.

Jacobson M (1991) Developmental neurobiology. 3d ed. New York: Plenum.

Jones EG (1985) The thalamus. New York: Plenum.

Keinänen K, Wisden W, Sommer B, Werner P, Herb A, Verdoorn TA, Sakmann B, Seeburg PH (1990) A family of AMPA-selective glutamate receptors. Science 249:556-560.

Koltchine V, Anantharam V, Wilson A, Bayley H, Treistman SN (1993) Homomeric assemblies of NMDAR 1 splice variants are sensitive to ethanol. Neurosci Lett 152:13-16.

Kutsuwada T, Kashiwabuchi N, Mori H, Sakimura K, Kushiya E, Araki K, Meguro H, Masaki H, Kumanishi T, Arakawa M, Mishina M (1992) Molecular diversity of the NMDA receptor channel. Nature 358:36-41.

Laurie DJ, Schrotz P (1994) Processing vertebrate embryonic and early postnatal tissue for in situ hybridisation. In: In situ hybridisation protocols for neurobiology (Wisden W, Morris, B, eds), in press. London: Academic.

McDonald JW, Johnston MV (1990) Physiological and pathophysiological roles of excitatory amino acids during central nervous system development. Brain Res Rev 15:41-70.

Meldrum B, Garthwaite J (1990) Excitatory amino acid neurotoxicity and degenerative disease. Trends Pharmacol Sci 11:379-387.

Mitani A, Andou Y, Kataoka K (1992) Selective vulnerability of hippocampal CAl neurons cannot be explained in terms of an increase in glutamate concentration during ischemia in the gerbil: brain microdialysis study. Neuroscience 48:307-313.
Monaghan DT (1991) Differential stimulation of [ $\left.{ }^{3} \mathrm{H}\right] \mathrm{MK}-801$ binding to subpopulations of NMDA receptors. Neurosci Lett 122:21-24.

Monaghan DT, Beaton JA (1992) Pharmacologically-distinct NMDA receptor populations of the cerebellum, medial thalamic nuclei and forebrain. Mol Neuropharmacol 2:71-75.

Monaghan DT, Olverman HJ, Nguyen L, Watkins JC, Cotman CW (1988) Two classes of $N$-methyl-D-aspartate recognition sites: differential distribution and differential regulation by glycine. Proc Natl Acad Sci USA 85:9836-9840.

Monyer H, Sprengel R, Schoepfer R, Herb A, Higuchi M, Lomeli $H$, Burnashev N, Sakmann B, Seeburg PH (1992) Heteromeric NMDA receptors: molecular and functional distinction of subtypes. Science 256:1217

Moriyoshi K, Masu M, Ishii T, Shigemoto R, Mizuno N, Nakanishi S (1991) Molecular cloning and characterization of the rat NMDA receptor. Nature 354:31-37.

Murphy DE, Hutchison AJ, Hurt SD, Williams M, Sills MA (1988) Characterization of the binding of $\left[{ }^{3} \mathrm{H}\right]$-CGS 19755: a novel $N$-methyl-D-aspartate antagonist with nanomolar affinity in rat brain. $\mathrm{Br} \mathrm{J}$ Pharmacol 95:932-938.

Nakanishi N, Axel R, Shneider NA (1992) Alternative splicing generates functionally distinct $N$-methyl-D-aspartate receptors. Proc Natl Acad Sci USA 89:8552-8556.

Oppenheim RW (1991) Cell death during development of the nervous system. Annu Rev Neurosci 14:453-501.

Paxinos G, Watson C (1986) The rat brain in stereotaxic coordinates, $2 \mathrm{~d}$ ed. Sydney: Academic.

Paxinos G, Törk I, Tecott LH, Valentino KL (1991) Atlas of developing rat brain. San Diego: Academic.

Perkel DJ, Hestrin S, Sah P, Nicoll RA (1990) Excitatory synaptic currents in Purkinje cells. Proc R Soc Lond [Biol] 241:116-121.

Sills MA, Fagg G, Pozza M, Angst C, Brundish DE, Hurt SD, Wilusz EJ, Williams M (1991) [ $\left.{ }^{3} \mathrm{H}\right] \mathrm{CGP} 39653$ : a new $N$-methyl-D-aspartate antagonist with low nanomolar affinity in rat brain. Eur J Pharmacol 192:19-24

Sommer B, Keinänen K, Verdoom TA, Wisden W, Burnashev N, Herb A, Köhler M, Takagi T, Sakmann B, Seeburg PH (1990) Flip and flop: a cell-specific functional switch in glutamate-operated channels of the CNS. Science 249:1580-1585.

Standaert DG, Testa C, Pennez JB Jr, Young AB (1993) Alternatively spliced isoforms of the NMDAR 1 glutamate receptor subunit: differential expression in the basal ganglia of the rat. Neurosci Lett 152: 161-164.

Staubli U (1992) A peculiar form of potentiation in mossy fiber synapses. Epilepsy Res [Suppl] 7:151-157.

Sugihara H, Moriyoshi K, Ishii T, Masu M, Nakanishi S (1992) Structures and properties of seven isoforms of the NMDA receptor generated by alternative splicing. Biochem Biophys Res Commun 185: $826-832$

Swanson LW (1992) Brain maps: structure of the rat brain. Amsterdam: Elsevier.

Tingley WG, Roche KW, Thompson AK, Huganir RL 1993) Regulation of NMDA receptor phosphorylation by alternative splicing of the C-terminal domain. Nature 364:70-73.

Watanabe M, Inoue Y, Sakimura K, Mishina M (1992) Developmental changes in distribution of NMDA receptor channel subunit mRNAs. Neuroreport 3:1138-1140.

Watanabe Y, Saito H, Abe K (1992) Effects of glycine and structurally related amino acids on generation of long-term potentiation in rat hippocampal slices. Eur J Pharmacol 223:179-184.

Wisden W, Morris B (1994) In situ hybridization with synthetic oligonucleotide probes. In: In situ hybridization protocols for neurobiology (Wisden W, Morris B, eds), in press. London: Academic.

Wisden W, Morris BJ, Hunt SP (1991) In situ hybridization with synthetic DNA probes. In: Molecular neurobiology - a practical approach (Chad J, Wheal H, eds), pp 205-226. Oxford: IRL.

Yamazaki M, Mori H, Araki K, Mori KJ, Mishina M (1992) Cloning, expression and modulation of a mouse NMDA receptor subunit. FEBS Lett 300:39-45.

Yuste R, Katz LC (1991) Control of postsynaptic $\mathrm{Ca}^{2+}$ influx in developing neocortex by excitatory and inhibitory neurotransmitters. Neuron 6:333-344.

Zalutsky RA, Nicoll RA (1992) Mossy fiber long-term potentiation shows specificity but no apparent cooperativity. Neurosci Lett 138: 193-197. 